\section{Ganging up on TB}

\section{By Lauren Martz, Staff Writer}

Work by researchers at Albert Einstein College of Medicine of Yeshiva University suggests that two FDA-approved antibiotics-meropenem and clavulanate-could be used in combination to overcome drugresistant Mycobacterium tuberculosis. ${ }^{1}$ Although the fact that meropenem must be given through i.v. could restrict use, researchers think the prevalence of drug-resistant disease makes testing the combination worthwhile.

Meropenem, marketed as Merrem by AstraZeneca plc, is a member of the carbapenem class of $\beta$-lactam antibiotics. $\beta$-lactam antibiotics have had little effect against tuberculosis infection because they are hydrolyzed by $M$. tuberculosis' $\beta$-lactamase (BLAC). ${ }^{2}$

To circumvent this problem, previous efforts have combined $\beta$-lactams such as amoxicillin with the BLAC inhibitor clavulanate. ${ }^{3}$ Clavulanate is not marketed alone, but it is available in combination with amoxicillin as Augmentin from GlaxoSmithKline plc.

In a paper published in Science, professor of biochemistry John Blanchard and colleagues at Albert Einstein suggest that combining clavulanate with meropenem could control the infection in areas that other $\beta$-lactams have failed. That is because meropenem is not as readily hydrolyzed by BLAC as other $\beta$-lactam antibiotics, because it is a relatively poor substrate for the enzyme.

In vitro, clavulanate significantly increased the minimum inhibitory concentration (MIC) of meropenem and other carbapenems. The BLAC inhibitor had little effect on the MIC of other classes of $\beta$-lactams such as penicillins.

Under aerobic conditions, meropenem plus clavulanate decreased the number of colony-forming units and eventually killed a strain of drug-sensitive $M$. tuberculosis over 9-12 days.

The combination also inhibited bacteria grown under anaerobic conditions, which is reflective of the persistent, nonreplicative state that is often resistant to antibiotic treatment.

Finally, meropenem plus clavulanate showed efficacy against 13 clinical isolates of drug-resistant TB strains with efficacy comparable to that seen in sensitive strains.

\section{Straight to the clinic}

Because both drugs used in the study are FDA approved, the Albert Einstein group thinks the combination is ready for clinical trials.

Brian Currie, assistant dean for clinical research and professor of clinical medicine and clinical epidemiology and population health at Albert Einstein, told SciBX that a study is being planned to test the combination of meropenem and Augmentin. The short-term African trial is expected to start mid-year.

Currie said the objective of the study is to show efficacy. "The drugs are FDA approved and relatively free of side effects. There shouldn't be any issues of toxicity or interactions between the two compounds," he said. Patients will receive the combination therapy for five to seven days.

Zhenkun Ma, CSO of the Global Alliance for TB Drug Development, concurred. "Human pharmacokinetic and metabolism information as well as short-term safety data are already available for both meropenem and clavulanate," he noted. "This is an advantage and could potentially translate into a quicker approval process for the meropenem-clavulanate combination than for a novel clinical entity."

Jose Garcia-Bustos, director of molecular drug discovery at GSK's Diseases of the Developing World Discovery Performance Unit, told $S c i B X$ that "clavulanate has been used for a large number of years with an excellent record of efficacy and safety, with the caveat that it was not developed for continuous use over such a long period."

$\mathrm{Ma}$ also noted that longer-term trials would be important. "Meropenem and clavulanate have only been tested for and are currently only approved for short-term use," he said. "Since TB requires many months of therapy, especially for drug-resistant disease, the long-term safety of these two agents must be investigated. New side effects could emerge with long-term administration."

John Rex, VP of clinical infection at AstraZeneca, was also cautious. "We have no safety data on the combination or on pharmacological interactions between the two compounds," he said. "Furthermore, meropenem does not have an indication for tuberculosis."

\section{Elusive pathogen}

Kenneth Coleman, CSO of Novexel S.A., also thinks there are a few reasons why the in vitro data might not translate into the clinic. "Most infecting bacteria exist within the body of the patient but outside of host cells. These are easily treated by a broad range of antibiotic classes. But $M$. tuberculosis exists both within and outside host cells," which is a problem because $\beta$-lactams do not penetrate mammalian cells.

As a result, said Coleman, a $\beta$-lactam "could reduce the bacterial burden by removing the extracellular $M$. tuberculosis but can never completely eliminate the organism. Bacteria can continue to grow and multiply inside cells and eventually break out. At best, meropenem/clavulanate treatment would relieve the symptoms. It would never cure the disease."

Novexel's NXL104, a BLAC inhibitor, is in Phase II testing to treat Gram-negative bacterial infections.

Ma said the adaptability M. tuberculosis could further complicate treatment. "The bacterium is a somewhat challenging organism that can adopt various noninheritable, drug-persistent forms in patients, 


\section{TARGETS \& MECHANISMS}

which are not yet fully understood," he said. "Additionally, Mycobacterium tuberculosis can also quickly develop inheritable mono- and multidrug resistance."

An additional challenge, said Coleman, is the bacterium's dormant phase. "When it is dormant, it is often not killed by treatments, so they can only be effective when the pathogen has come out of dormancy," which is why it needs to be treated for so long.

\section{Drug delivery}

Even if the meropenem and clavulanate combination produces strong clinical data, there remain logistical issues that could hamper use of the cocktail.

The main issue is that meropenem is only available in i.v. formulations. As a result, said Ma, "its potential for widespread use may be limited, especially in resource-limited settings."

Coleman agreed, noting that i.v. delivery "increases the cost of therapy enormously compared to oral agents and requires the patient to either stay in a hospital or report to a clinic two to three times daily for dose administration. Since TB is predominantly a Third World disease, the cost of such therapy would be prohibitive," he said.

Setting aside the issue of cost, Coleman told SciBX that the months of i.v. therapy "would most likely need an in-dwelling i.v. catheter, which would put a large portion of patients at risk for secondary infection by other bacteria."

The challenges are worth tackling, said Martin Pan, manager of discovery medicine at GSK's Diseases of the Developing World unit. Although a lack of oral formulations restricts meropenem to the hospital setting, "this would be enough to save the lives of many patients with drug-resistant TB who are already hospitalized," he said.

The GlaxoSmithKline researchers told SciBX that the Diseases of the Developing World unit is working with the authors of the paper to help the progress of this potential new treatment option.

David Schoenhaut, assistant director of the office of biotechnology at Albert Einstein, told SciBX that a U.S. provisional patent application has been filed, and the IP is available for licensing.

Martz, L. SciBX 2(10); doi:10.1038/scibx.2009.390

Published online March 12, 2009

\section{REFERENCES}

1. Hugonnet, J. et al. Science; published online Feb. 23, 2009; doi:10.1126/science.1167498

Contact: John S. Blanchard, Albert Einstein College of Medicine of Yeshiva University, Bronx, N.Y. e-mail: blanchar@aecom.yu.edu

2. Cole, S. et al. Nature 393, 537-544 (1998)

3. Cynamon, M. \& Palmer, G. Antimicrob. Agents Chemother. 23, 429-431 (1983)

\section{COMPANIES AND INSTITUTIONS MENTIONED}

Albert Einstein College of Medicine of Yeshiva University, Bronx, N.Y. AstraZeneca plc (LSE:AZN; NYSE:AZN), London, U.K. GlaxoSmithKline plc (LSE:GSK; NYSE:GSK), London, U.K. Global Alliance for TB Drug Development, New York, N.Y. Novexel S.A., Romainville, France 